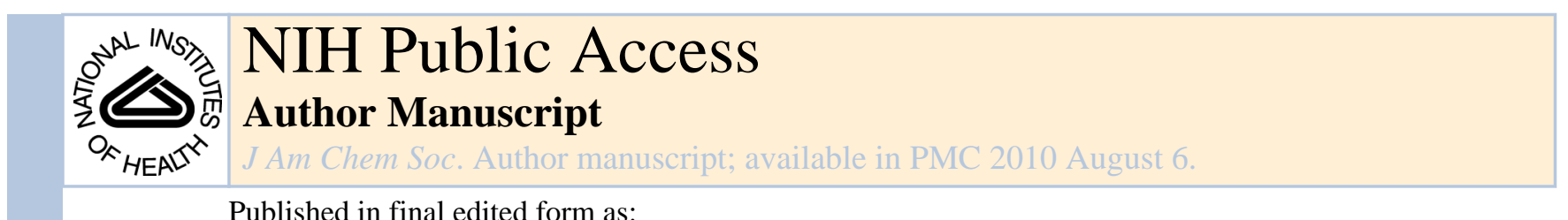

Published in final edited form as:

J Am Chem Soc. 2008 March 19; 130(11): 3262-3263. doi:10.1021/ja710065h.

\title{
Asymmetric Synthesis of Bicyclic Amidines via Rhodium- Catalyzed [2+2+2] Cycloaddition of Carbodiimides
}

\author{
Robert T. Yu and Tomislav Rovis ${ }^{*}$ \\ Department of Chemistry, Colorado State University, Fort Collins, Colorado 80523
}

Recent advances in the field of transition metal-catalyzed cycloadditions have made them among the most efficient methods to assemble polycyclic carbocycles and heterocycles. ${ }^{1}$ Cycloadditions employing carbodiimides are surprisingly scarce in the literature. ${ }^{2} \mathrm{An}$ intramolecular Pauson-Khand-type reaction of alkynyl carbodiimides has recently been described, ${ }^{3}$ while $[2+2+2]$ cycloadditions of diynes and carbodiimides have been documented to provide mostly inseparable mixtures. ${ }^{4,5}$ To the best of our knowledge, there have been no reports of successful enantioselective $[m+n+o]$ type cycloadditions involving carbodiimides as a $2 \pi$ component.

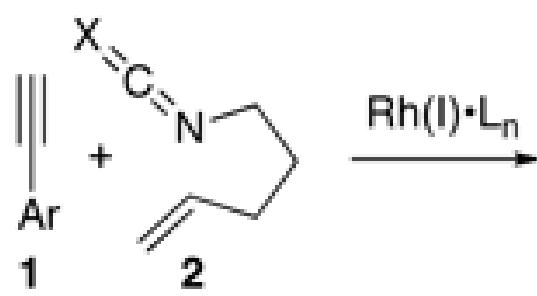<smiles>[X]C1=CC(Br)CC2CCCN12</smiles><smiles>[X]C1=CC(Br)N2CCC[C@H]2C1</smiles>

\section{- Previous work $(X=O)$}

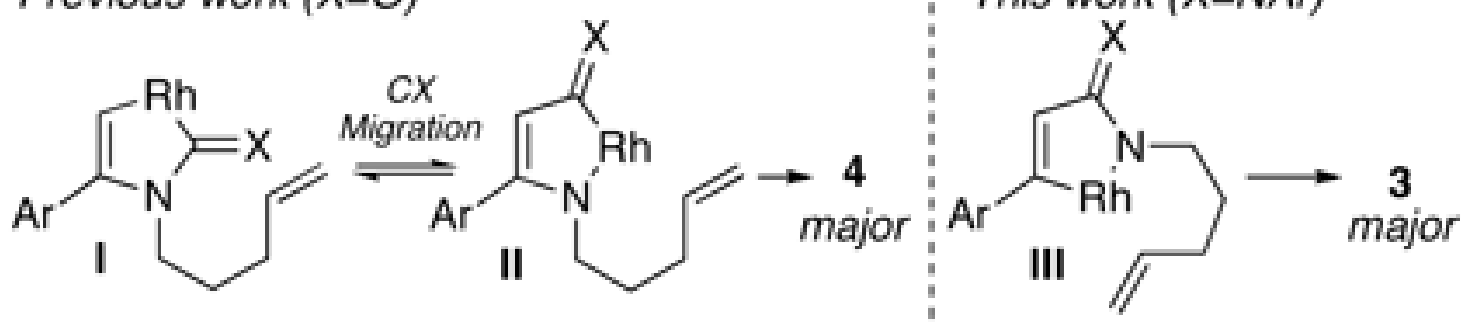

We previously described an unusual cycloaddition between phenyl acetylene 1a and isocyanate $\mathbf{2}(\mathrm{X}=\mathrm{O}$, eq 1$)$, where the major pathway proceeds via metalacycles $\mathbf{I}$ and II involving a $\mathrm{CO}$ migration process. ${ }^{6}$ The resulting cycloaddition affords product $\mathbf{4}(\mathrm{X}=\mathrm{O})$ in good efficiency while cycloadduct $\mathbf{3}$ can only be formed as the minor component (3:4 =1:7, $\mathrm{Ar}=\mathrm{Ph}$ ). In an effort to selectively access products of type $\mathbf{3}$, we envisioned that a cycloaddition employing carbodiimides $(2, \mathrm{X}=\mathrm{NAr})$ should favor the formation of metalacycle III by placing the bulky imido moiety further away from the rhodium center (I vs. III). Herein, we report the successful application of this strategy, providing a

rovis@lamar.colostate.edu.

Supporting Information Available: Experimental procedures, characterization, ${ }^{1} \mathrm{H}$ and ${ }^{13} \mathrm{C}$ NMR spectra are provided. This material is available free of charge via the Internet at http://pubs.acs.org. 
complementary selectivity to the cycloaddition previously described using isocyanates. ${ }^{7}$ Further, this reaction offers a novel entry into the asymmetric synthesis of bicyclic amidines $(3, \mathrm{X}=\mathrm{NAr}){ }^{8}$
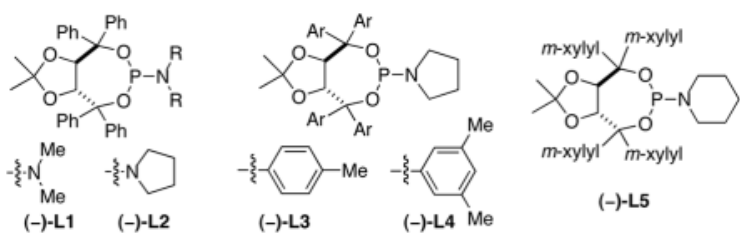

Our investigations began with the cycloaddition of phenyl acetylene 1a and the phenylsubstituted pentenyl carbodiimide $\mathbf{2 a}$ employing our previously developed reaction conditions (entries $1-2$, Table 1). ${ }^{6 \mathrm{~b}}$ These conditions afford the desired bicyclic amidine 3 in moderate yields with the ligand $\mathbf{L} \mathbf{2}$ providing the highest enantioselectivity. The $p$-tolTADDOL derived ligand $\mathbf{L} \mathbf{3}$ provides a very efficient reaction with half the catalyst loading and shorter reaction times (entry 3 ). Further optimization led to the identification of $m$-xylylTADDOL derivative $\mathbf{L} \mathbf{4}$ as the best ligand, affording the bicyclic amidine with good chemical yield and excellent enantioselectivity (entry 4). The amino group on the ligand proves to have a significant effect on the reaction; replacing the pyrrolidinyl moiety with the piperidine can further improve the product selectivity for $\mathbf{3}$, although the enantioselectivity decreases (entry 5). It is significant to note that the type $\mathbf{4}$ product resulting from a rare isocyanide (CNR) migration ${ }^{9}$ can be observed in the reaction mixture as the minor component.

Table 2 summarizes the scope of the enantioselective $[2+2+2]$ cycloaddition of phenyl acetylene 1a and a variety of aryl-substituted carbodiimides. The reaction tolerates both electron-rich and electron-poor substituents at various positions to afford bicyclic amidines $\mathbf{3}$ in good yields and excellent enantioselectivity (entries 1-5). Aryl carbodiimides with strong electron-withdrawing groups provide much greater product selectivity (entries 4-5). For larger scale reactions, the catalyst loading may be reduced to $1 \mathrm{~mol} \%\left[\mathrm{Rh}\left(\mathrm{C}_{2} \mathrm{H}_{4}\right)_{2} \mathrm{Cl}\right]_{2}$ with virtually identical yield and enantioselectivity.

For further substrate development, we chose $o$-anisidine derived carbodiimide as the standard cycloaddition partner. This selection was based on the optimal enantioselectivity obtained and their potential roles as an oxidatively cleavable protecting group of the resulting cycloadducts. ${ }^{10}$

The asymmetric synthesis of amidine $\mathbf{6 a}$ possessing a nitrogen-substituted quaternary center can be achieved in high efficiency from the corresponding disubstituted alkenyl carbodiimide (eq 2). ${ }^{6 c}$ Although a much more sluggish reaction, cycloaddition of carbodiimide $\mathbf{8}$ to construct the desired [4.4.0] bicyclic amidine 9a proceeds in a moderate yield with excellent enantiocontrol (eq 3).

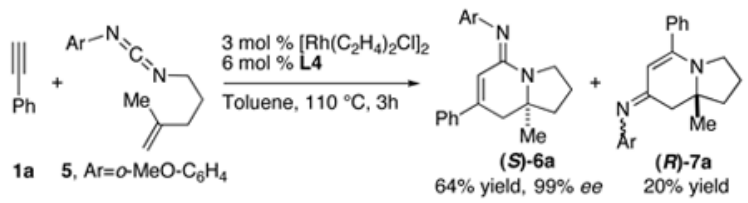




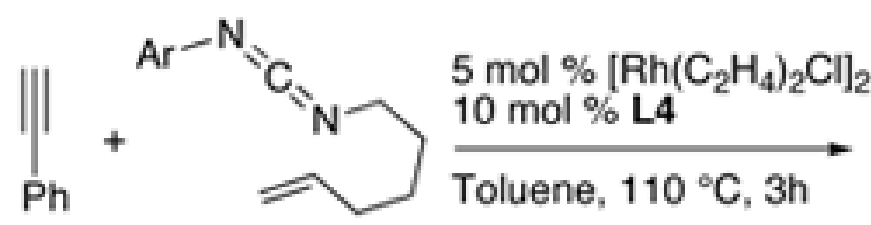

1a $8, \mathrm{Ar}=0-\mathrm{MeO}-\mathrm{C}_{6} \mathrm{H}_{4}$

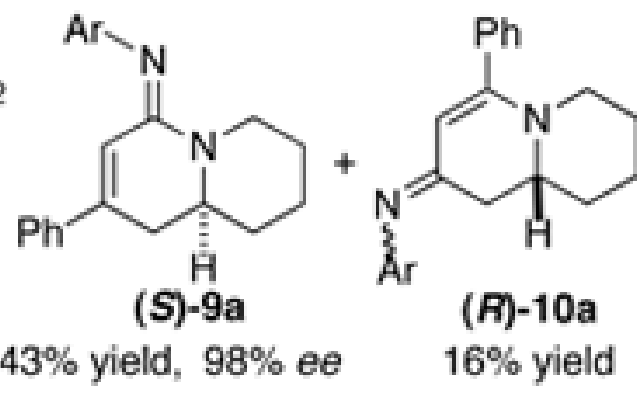

(3)

The cycloadditions of a variety of terminal alkynes and carbodiimides $\mathbf{2 c}$ and $\mathbf{5}$ were examined (Table 3). The electronic and steric effects of alkynyl partners play important roles to the reaction outcomes. Aryl acetylenes substituted with various electron-poor groups participate in the cycloaddition readily to furnish almost exclusively the bicyclic amidine $\mathbf{3}$ or 6 with good yields and excellent enantioselectivity (entries $1-6,14-15$ ). ${ }^{11}$ The reactions of alkyne $\mathbf{1 h}$, which possesses a moderate $\sigma$-withdrawing group, proceed with the same efficiency to afford the desired amidines in good product ratio (entries 7, 16). $m$-Tolyl acetylene $\mathbf{1} \mathbf{i}$, which is slightly more electron-rich than $\mathbf{1 a}$, and ethynyl thiophene $\mathbf{1} \mathbf{j}$, which is sterically smaller than $\mathbf{1 a}$, undergo the cycloaddition to provide the corresponding amidines in high enantiomeric excess with product ratio similar to those with 1a (entries 8,10 ). The moderate product ratio can be greatly improved while maintaining the excellent enantiocontrol by using the $o-\mathrm{CF}^{3}$-phenyl carbodiimide $2 \mathrm{e}$ (entries 9,11 ). On the other hand, the reaction of electron-rich aryl acetylene $1 \mathbf{k}$ proceeds with an opposite product selectivity (entries 12-13), a trend that is consistent with our previous study ${ }^{6 \mathrm{~b}}$ Cycloadditions with alkyl acetylenes require a slightly higher catalyst loading to ensure complete conversion (entries 17-22), but generate bicyclic amidines 3 with high efficiency (88-96\% ee).

The resulting bicyclic amidines 3 are potentially useful chiral building blocks. Under appropriate conditions, the olefin and the amidine moiety can each be selectively reduced while leaving the other functionality untouched for further transformation (eq 4).

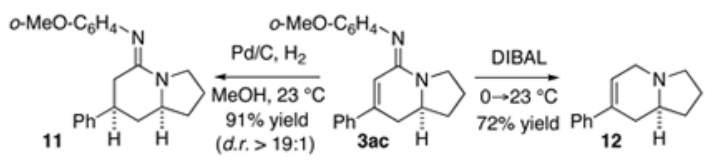

In summary, we have developed the first enantioselective $[2+2+2]$ cycloaddition utilizing carbodiimides to give bicyclic amidines with excellent enantiocontrol. Observation of the isocyanide migration process during the cycloaddition is notable. Studies to explore the synthetic utility of bicyclic amidines $\mathbf{3}$ are ongoing.

\section{Supplementary Material}

Refer to Web version on PubMed Central for supplementary material. 


\section{Acknowledgments}

Dedicated with deep respect to the memory of our friend and colleague Professor Albert I. Meyers (1932-2007). We thank NIGMS (GM080442), Eli Lilly, Boehringer Ingelheim and Johnson \& Johnson for support. TR is a fellow of the Alfred P. Sloan Foundation and thanks the Monfort Family Foundation for a Monfort Professorship.

\section{References}

1. For recent reviews: (a) Aubert C, Buisine O, Malacria M. Chem Rev 2002;102:813. [PubMed: 11890758] (b) Murakami M. Angew Chem Int Ed 2003;42:718. (c) Nakamura I, Yamamoto Y. Chem Rev 2004;104:2127. [PubMed: 15137788] (d) Gandon V, Aubert C, Malacria M. Chem Commun 2006:2209. (e) Chopade PR, Louie J. Adv Synth Catal 2006;348:2307.

2. Intermolecular cyclotrimerization of alkynes and carbodiimides: (a) Hong P, Yamazaki H. Tetrahedron Lett 1977:1333. (b) Hoberg H, Burkhart G. Synthesis 1979:525. (c) Diversi P, Ingrosso G, Lucherini A, Malquori S. J Mol Catal 1987;40:267. (d) Takahashi T, Tsai F, Li Y, Wang H, Kondo Y, Yamanaka M, Nakajima K, Kotora M. J Am Chem Soc 2002;124:5059. [PubMed: 11982370]

3. (a) Mukai C, Yoshida T, Sorimachi M, Odani A. Org Lett 2006;8:83. [PubMed: 16381573] (b) Saito T, Sugizaki K, Otani T, Suyama T. Org Lett 2007;9:1239. [PubMed: 17348662] (c) Aburano D, Yoshida T, Miyakoshi N, Mukai C. J Org Chem 2007;72:6878. [PubMed: 17691742]

4. See text: (a) Yamamoto Y, Kinpara K, Saigoku T, Takagishi H, Okuda S, Nishiyama H, Itoh K. J Am Chem Soc 2005;127:605. [PubMed: 15643884] (b) Bonaga LVR, Zhang HC, Moretto AF, Ye H, Gauthier DA, Li J, Leo GC, Maryanoff BE. J Am Chem Soc 2005;127:3473. [PubMed: 15755167]

5. A successful cycloaddition of solid supported diynes and carbodiimides was reported: Young DD, Deiters A. Angew Chem Int Ed 2007;46:5187.

6. (a) Yu RT, Rovis T. J Am Chem Soc 2006;128:2782. [PubMed: 16506740] (b) Yu RT, Rovis T. J Am Chem Soc 2006;128:12370. [PubMed: 16984159] (c) Lee EE, Rovis T. Org Lett. In press.

7. For other metal catalyzed [2+2+2] cycloadditions involving isocyanates. Co: (a) Earl RA, Vollhardt KPC. J Org Chem 1984;49:4786.(b) ref. 2a. (c) ref. 4b. Ru: (d) Yamamoto Y, Takagishi H, Itoh K. Org Lett 2001;3:2117. [PubMed: 11418063] (e) ref. 4a. Ni: (f) Hoberg H, Oster BW. Synthesis 1982:324. (g) Duong HA, Cross MJ, Louie J. J Am Chem Soc 2004;126:11438. [PubMed: 15366880] Rh: (h) Tanaka K, Wada A, Noguchi K. Org Lett 2005;7:4737. [PubMed: 16209523]

8. Synthesis of chiral amidines: (a) Meyers AI, Miller DB, White FH. J Am Chem Soc 1988;110:4778. (b) Convery MA, Davis AP, Dunne CJ, MacKinnon JW. Chem Commun 1994:2557. (c) Papandreou G, Tong MK, Ganem B. J Am Chem Soc 1993;115:11682. (d) Ostendorf M, Dijkink J, Rutjes FPJT, Hiemstra H. Eur J Org Chem 2000:115. (e) Heck M, Vincent SP, Murray BW, Bellamy F, Wong C, Mioskowski C. J Am Chem Soc 2004;126:1971. [PubMed: 14971930] (f) Kumagai N, Matsunaga S, Shibasaki M. Angew Chem Int Ed 2004;43:478. (g) Chang S, Lee M, Jung DY, Yoo EJ, Cho SH, Han SK. J Am Chem Soc 2006;128:12366. [PubMed: 16984157]

9. (a) Barnhart RW, Bosnich B. Organometallics 1995;14:4343. (b) Tanaka K, Fu GC. Chem Commun 2002:684.

10. (a) Kobayashi S, Ishitani H, Ueno M. J Am Chem Soc 1998;120:431. (b) Saito S, Hatanaka K, Yamamoto H. Org Lett 2000;2:1891. [PubMed: 10891184]

11. ortho-Substituted aryl alkynes are not tolerated under current conditions. Cycloaddition with 1chloro-2-ethynyl benzene gives product 3 in only 35\% yield and 31\% ee while 2-ethynyltoluene provides no cycloadduct. 
Table 2

Carbodiimide Scope

\begin{tabular}{|c|c|c|c|c|}
\hline entry & $\mathbf{R}$ & $3: 4^{b}$ & yield $(\%)$ of $3^{c}$ & $e e(\%)$ of $3^{d}$ \\
\hline 1 & $p$-OMe, $\mathbf{2 b}$ & $3.6: 1$ & 70 & 94 \\
\hline 2 & $o$-OMe, $2 \mathrm{c}$ & 3.8: 1 & $68(62)^{e}$ & $98(96)^{e}$ \\
\hline 3 & $m-\mathrm{Cl}, \mathbf{2 d}$ & $3.4: 1$ & 67 & 97 \\
\hline 4 & $o-\mathrm{CF}_{3}, \mathbf{2 e}$ & 9.4: 1 & 82 & 97 \\
\hline $5^{f}$ & $p-\mathrm{CN}, \mathbf{2 f}$ & $9.5: 1$ & 55 & 92 \\
\hline
\end{tabular}

${ }^{a}$ Conditions: 1 (2 equiv), $2(0.16 \mathrm{mmol}), \mathrm{Rh}$ catalyst, $\mathrm{L}$ in $\mathrm{PhMe}$ at $110^{\circ} \mathrm{C}$.

${ }^{b}$ Product selectivity (3: 4) is determined by ${ }^{1} \mathrm{H}$ NMR of the unpurified reaction mixture.

$c_{\text {Isolated yield. }}$

$d_{\text {Determined by HPLC analysis using a chiral stationary phase. }}$

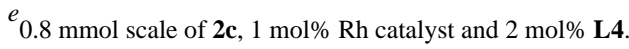

$f_{5 \mathrm{~mol}} \%$ Rh catalyst and $10 \mathrm{~mol} \% \mathbf{L 4}$. 


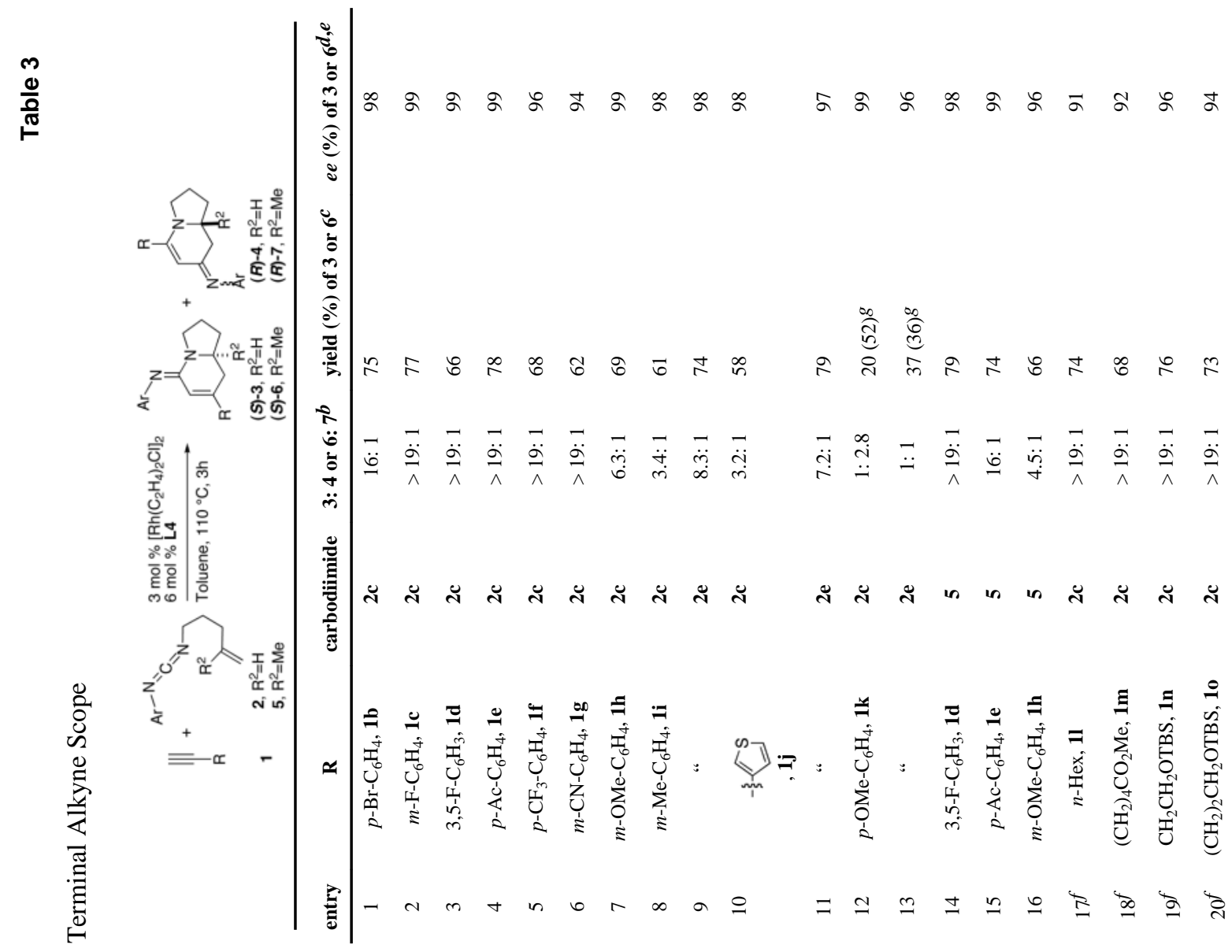




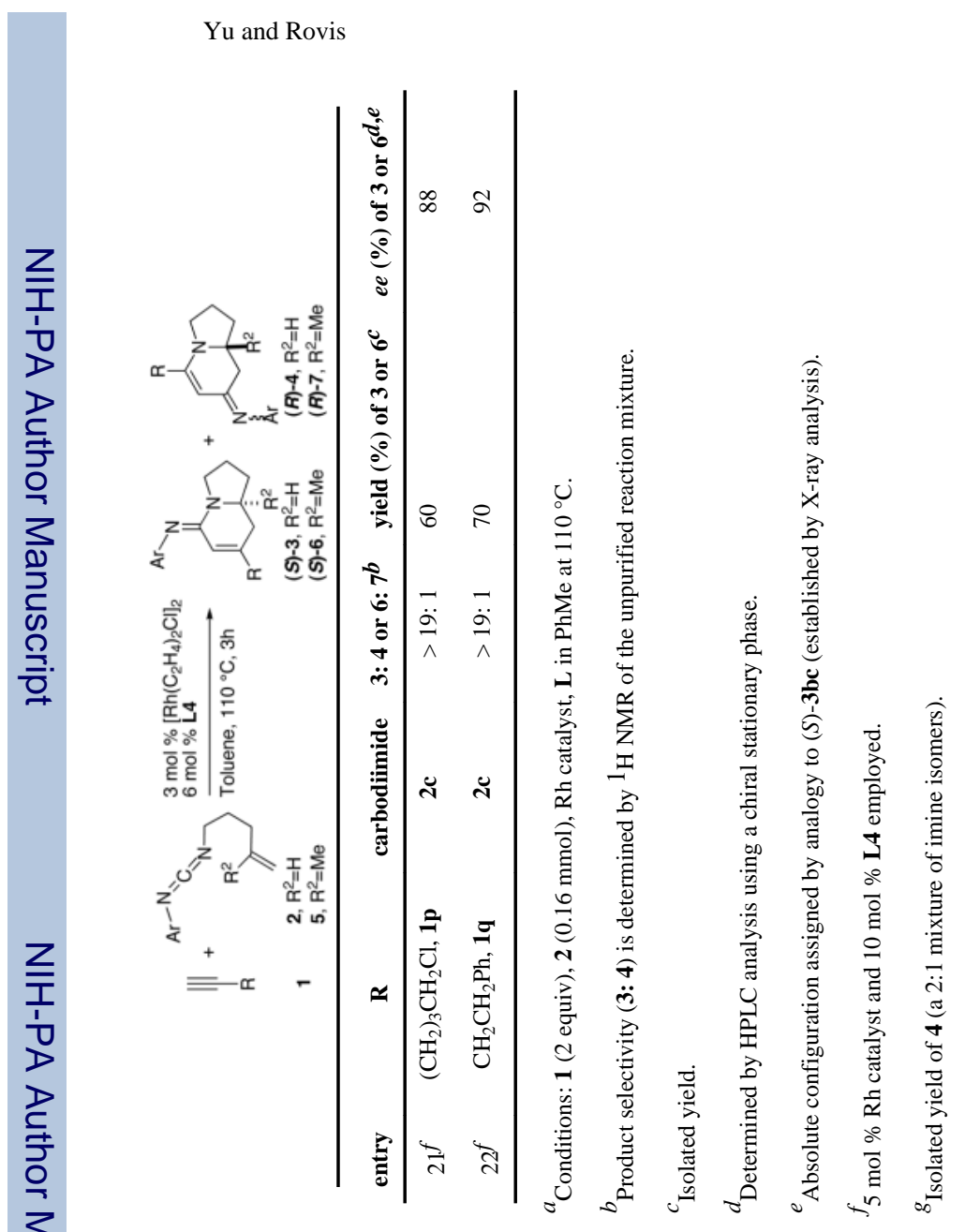

Page 8 